\title{
Recurrent Malignant Bladder Neoplasm
}

National Cancer Institute

\section{Source}

National Cancer Institute. Recurrent Malignant Bladder Neoplasm. NCI Thesaurus. Code C9266.

The reemergence of a malignant bladder neoplasm after a period of remission. 